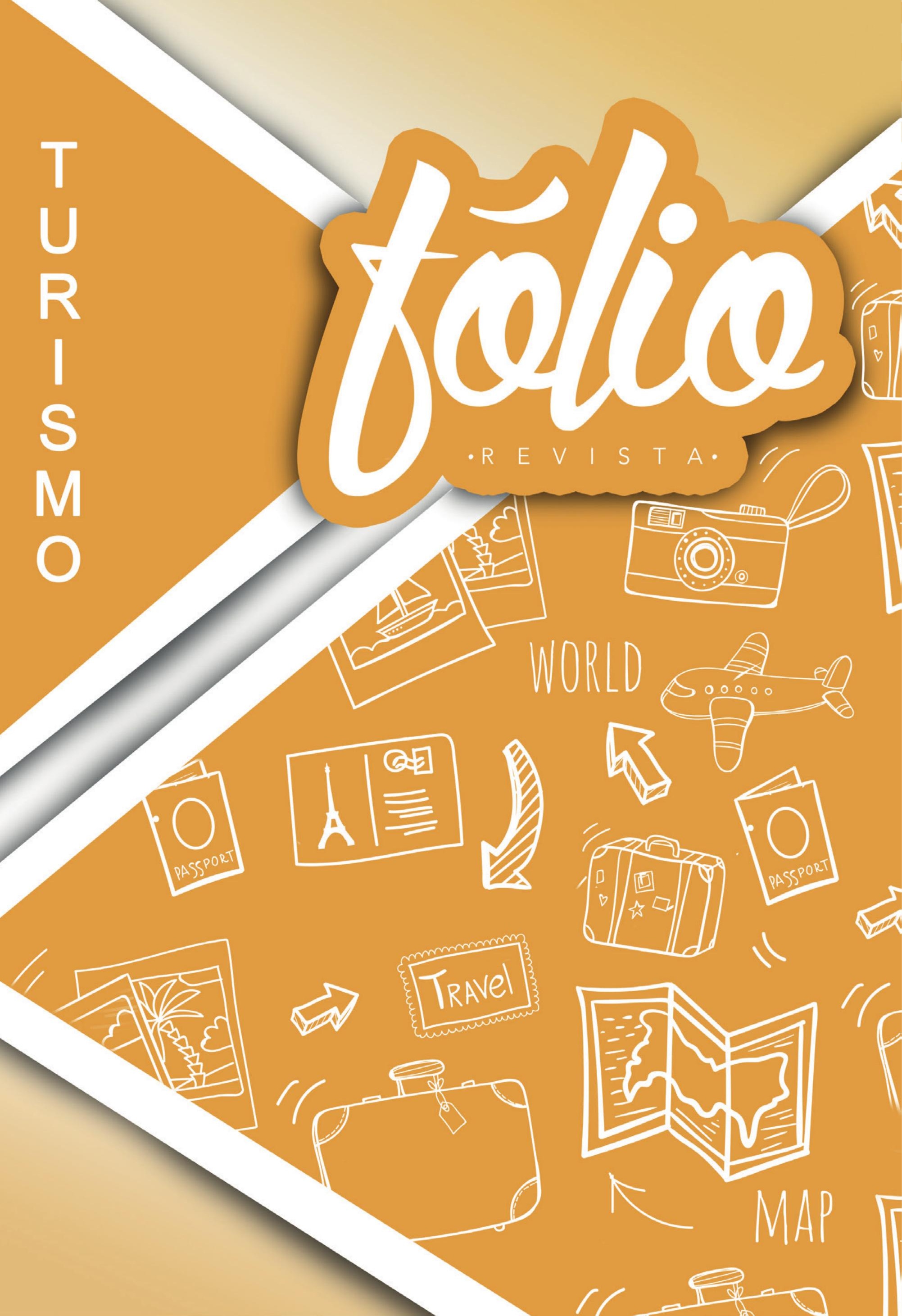




\title{
Turismo de eventos e o cenário do segmento geek: um estudo de caso da Comic Con Experience São Paulo - SP
}

\section{Event tourism and the geek segment scenario: $a$ case study of the Comic Con Experience São Paulo - SP}

\author{
Aryelle dos Santos Vaniel ${ }^{1}$ \\ Elenara Viera de Viera ${ }^{2}$
}

\section{Resumo}

Com o crescimento de realizações de eventos no país, o setor de eventos vem apostando em novos públicos e temas. Dessa forma o presente artigo tem por objetivo apresentar o estudo realizado em relação aos eventos geeks/nerds, com foco em especial na Comic Con Experience realizada na cidade de São Paulo em 2016. O objetivo geral da pesquisa foi o de analisar um evento voltado a este público. Como objetivos específicos, pretendeu-se: caracterizar o perfil do público; apresentar as estruturas físicas e organizacionais do evento; e descrever os motivos que caracterizam os deslocamentos até o evento. Para isso, o estudo se utilizou de um questionário quantitativo com avaliação do perfil do público participante, suas motivações e satisfações com o evento. Os resultados obtidos possibilitaram determinar esse público participante como jovens, com educação superior e motivados a participar no evento para ter contato com seus ídolos.

Palavras chaves: Eventos. Geeks. Motivação. Turismo de Eventos.

\section{Abstract}

With the growth of events in the country, the events sector is betting on new audiences and themes. This article aims to present the study carried out in relation to the geeks / nerds events, focusing in particular on the Comic Con Experience held in the city of São Paulo in 2016. The general objective of the research was to analyze an event focused on this public. As specific objectives, it was intended: to characterize the profile of the public; present the physical and organizational structures of the event; and describe the reasons that characterize the movements to the event. For this, the study used a quantitative questionnaire with evaluation of the profile of the participating public, their motivations and satisfactions with the event. The results obtained allowed to determine this participant audience as young people, with higher education and motivated to participate in the event to have contact with their idols.

Keywords: Events. Geeks. Motivation. Tourism of Events.

\footnotetext{
1 Graduada em Bacharelado em Turismo do Centro Universitário Metodista Sul - IPA. Atualmente, atua junto a uma operadora como agente de viagens. E-mail para contato: aryelle.vaniel@gmail.com.

2 Professora do Centro Universitário Metodista IPA. E-mail: elenara.viera@ipa.metodista.br
} 


\section{Introdução}

( presente artigo tem por objetivo apresentar os resultados obtidos durante o Trabalho de Conclusão do Curso de Bacharelado em Turismo do Centro Universitário Metodista - IPA. Assim, o trabalho realizado teve foco no setor de Eventos em especial os voltados ao tema de eventos geek/nerd ${ }^{2}$. No quarto trimestre de 2016, os turistas nacionais corresponderam a $94 \%$ da demanda total, e os estados mais procurados para realizações de eventos foram o Rio de Janeiro, São Paulo e Ceará (BRASIL, 2017). De acordo com dados publicados pela Internacional Congress and Convention Association (ICCA) ${ }^{3}$, São Paulo em 2015 manteve a liderança no ranking das cidades brasileiras que mais realizaram eventos no padrão da ICCA, totalizando 78 eventos, empatando com a cidade de Vancouver no Canadá. A liderança nas Américas é da cidade de Lima no Peru, com 82 eventos realizados no ano de 2015.

Com a alta demanda por eventos no país, o mercado vem apostando em diversos públicos sendo os nerds e geeks, foco deste trabalho, uma categoria em ascensão (BRASIL, 2016). Esse público é fanático por produtos ligados a cultura pop e com poder aquisitivo para isso, e empresários vem acreditando no setor para atender aos desejos dos compradores (ZARA, 2014). Segundo Sheu e Chu (2017), nos últimos anos foi possível observar o valor dado e a influência do mercado na área de entretenimento, em especial às animações, revistas em quadrinhos e jogos, chamados de animations, comics and games (ACG). Os autores também afirmam que essa indústria não se restringe a apenas um país ou região, sendo vista como global, pois sua diversidade de produtos permite ganhos e oportunidades de negócios.

Com o crescimento do consumo por par-

2 Aparece como sinônimo de nerd e como uma espécie de subgrupo sendo utilizado para designar jovens avidamente interessados em tecnologia, computadores, etc.

3 Disponível em: https://www.mercadoeeventos.com.br/_ destaque_/slideshow/veja-as-10-cidades-brasileiras-mais-bemcolocadas-no-ranking-da-icca/ Acesso 2 maio 2017. te deste grupo, a empresa Omelete 4 investiu na Comic Con Experience, um evento que segue os moldes iguais aos promovidos nos Estados Unidos, que reúnem conteúdo e atrações tanto estrangeiras como nacionais, abordando temas desde quadrinhos a filmes, séries, games, anime, e música. Esta é sua terceira edição no Brasil e é considerado o maior evento do país na categoria nerd/geek.

A linha de pesquisa abordada foi à gestão da tecnologia, empreendedorismo e desenvolvimento sustentável, objetiva no estudo do planejamento e gestão da tecnologia do Turismo e seus processos de comunicação e mercadológicos nas organizações públicas, privadas e do terceiro setor, permeados pela inovação e visão empreendedora, com vistas à sustentabilidade (IPA, 2016).

Os procedimentos metodológicos utilizados foram de pesquisa exploratória, reconhecimento em campo do local, e a coleta de dados, feita através que um questionário pré-elaborado, com os participantes do evento.

\section{Referencial teórico}

Segundo o Instituto Brasileiro de Turismo (EMBRATUR) (BRASIL, 2008) o Turismo é considerado uma importante atividade econômica mundial, e é responsável pela movimentação de miIhões de pessoas e, consequentemente, gerador de rendas e empregos nos destinos visitados, sendo eles nacionais e/ou internacionais. Os deslocamentos gerados pela atividade variam de motivações, sendo as principais buscas por sol e praia, lazer, ecoturismo, até a realização de negócios e/ ou para a participação em eventos e feiras. Como passo fundamental para se tratar do Turismo como atividade econômica é necessário saber as reais motivações da demanda, com técnicas modernas de marketing é possível fazer a elaboração do perfil do turista buscando dimensionar os vários segmentos e com isso surgiu um novo fenômeno: os eventos como motivação para viajar

4 Site de entretenimento voltado a cultura pop, como filmes, séries e quadrinhos. 
(ANDRADE, 2002).

Segundo Zanella (2003), evento é uma concentração ou reunião formal e solene de pessoas e/ou entidades realizada em data e local especial, com o objetivo de celebrar acontecimentos importantes e significativos, assim como estabelecer contatos de natureza comercial, cultural, esportiva, social, familiar, religiosa, científica etc. Segundo Getz (2008), o Turismo de Eventos pode adotar duas perspectivas. A primeira resulta do comportamento dos consumidores e define-se pelo fenômeno das viagens relacionadas aos eventos: quem é motivado a viajar para participar num evento, os motivos que o levam a consumir esse evento e as características e efeitos das viagens desse consumidor. A segunda perspectiva está relacionada com as organizações turísticas e outras agências que produzem ou promovem eventos como atrações e, ainda, os criadores de imagem para comunidades e destinos que também contribuem para a promoção do lugar. Sendo assim, essas duas perspectivas nos mostram os dois lados dos eventos: os consumidores e suas motivações que o levam a deslocar-se para a participação dos eventos, podendo se encaixar neste contexto o público nerd/geek. E em segundo, os promotores dos eventos: as agências e produtores que montam as estruturas e divulgam para este público especifico.

São várias as ciências sociais que tentam explicar e caracterizar o fenômeno da motivação. A psicologia e a sociologia, por exemplo, definem as motivações como sendo emocionais e cognitivas (AJZEN; FISHBEIN, 1977) ou intrínsecas e extrínsecas ao indivíduo (GNOTH, 1997). Para Iso-Ahola (1982), a motivação consiste num fator interno do indivíduo, onde são dirigidos e integrados comportamentos individuais. Yoon (2005) refere-se que a motivação consiste numa necessidade psicológica e biológica de cada indivíduo. Sendo assim, motivação consiste na vontade de adotar elevados níveis de esforço que conduzam a satisfação de algumas necessidades individuais. Essas necessidades individuais consistem num estado interno que determina o grau de atração de um resultado, ou seja, consistem no estado interno da pessoa que faz com que certos objetivos ou resultados sejam desejados e procurados (FER-
REIRA E NEVE, 2002).

Em um ambiente de eventos, a identificação das necessidades e expectativas dos visitantes, em conjunto com o marketing, torna-se o ponto de partida para satisfazer as suas motivações e chegar ao público alvo (GRENHAS, 2013). Para Iso-Ahola (1982), alcançar as necessidades e motivações dos visitantes deve ser o principal objetivo e preocupação da organização do evento. São vários os autores que realizam estudos para identificar a motivação dos visitantes. Do ponto de vista de MacCannel (1977) os visitantes estão motivados para fugir da rotina do dia a dia, procurando pela autenticidade das experiências. Lundberg (1971) indica como fatores motivacionais a socialização, união, novidade/curiosidade. Já Scott (1996) identifica como fatores motivacionais a fuga da rotina, curiosidade, união familiar e socialização. Segundo Lee e Lee (2001), a realização de um estudo voltado para as motivações permite aos gestores dos eventos identificarem os pontos fortes e fracos do festival e ajuda-os a garantir a satisfação dos visitantes.

\section{Metodologia}

O presente trabalho utilizou-se da pesquisa exploratória e descritiva para um Estudo de Caso. A pesquisa exploratória tem por objetivo proporcionar informações sobre o assunto a ser investigado. Neste Estudo de Caso, os eventos nerd/geek, em especial a Comic Con Experience, permitiu uma familiarização com o problema, tornando- o mais explícito. A pesquisa possibilitou estudar uma unidade social, neste caso o público nerd/ geek, e conhecer de forma profunda suas características em determinadas situações, neste caso, suas participações nos eventos temáticos voltados a eles.

Para a coleta de dados foi aplicado uma entrevista estruturada com os participantes do evento. A padronização se refere à obtenção das respostas através de um mesmo formulário para todos os participantes assim havendo a possibilidade de que as mesmas sejam comparadas (MARCONI E LAKATOS, 2007).

O evento ocorreu nos dias 1, 2, 3 e 4 de de- 
zembro de 2016, das $10 \mathrm{~h}$ às $20 \mathrm{~h}$. A amostra foi eleita de forma probabilística levando em conta o volume de participantes nos quadro dias. A segunda edição, realizada em dezembro de 2015, contou com a participação de 142.000 (cento e quarenta e dois mil) geeks/nerds. Para se alcançar um nível de 95\% de confiabilidade e 5\% de erro amostral, seriam necessárias 384 (trezentos e oitenta e quatro) entrevistas. A edição de 2016 teve a participação de 196.000 (cento e noventa e seis mil), o que necessitaria do mesmo número de entrevistas.

A finalidade era coletar dados em todos as diferentes áreas do evento para se obter um resultado mais homogêneo. Como a pesquisadora apenas compareceu a um dos quatro dias do evento, e não haveria tempo hábil para a coleta da totalidade das entrevistas devido ao tempo de espera nas filas e em cada área do evento (em torno de $2 \mathrm{~h}$ até 4 h), optou-se por uma amostra probabilística com $90 \%$ de confiabilidade e $10 \%$ de erro amostral, totalizando 68 entrevistas. Porém, a pesquisadora conseguiu coletar 140 (centro e quarenta).

Após a coleta de dados, os resultados foram analisados da seguinte forma: o perfil dos entrevistados foi categorizado e apresentado em gráficos por meio de frequência simples e o motivo de deslocamento e satisfação com o evento, que na entrevista estruturada aparecia em escala ordinal, foram apresentados por meio de média, mediana, moda e desvio padrão.

\section{Resultados}

O trabalho teve por objetivo geral o de analisar um evento voltado ao público nerd/geek. A metodologia utilizada foi à pesquisa exploratória e descritiva, utilizando-se de uma entrevista estruturada com 140 (cento e quarenta) participantes durante o evento. $O$ primeiro objetivo era caracterizar o perfil do público. Em relação ao gênero, o público do gênero masculino figura como maioria presente no evento, sendo a maior presença de pessoas com idade entre 26 a 30 anos. Já o gênero feminino contava com um público com idades entre 20 a 25 anos em sua maioria. Em relação à escolaridade, destaca-se para ambos os gêneros o Ensino Superior, seguido de estudantes do Ensino Médio. Quanto à profissão, foi respondida pela maioria como sendo estudante seguido de cargos como técnicos e programadores, evidenciando assim, como descrito na teoria, uma característica deste público que é sua paixão por tecnologia. Em relação à região de origem, houve maior participação de pessoas da região sudeste do país, sendo, maioria, moradores da cidade de São Paulo ou cidades próximas. A região sul do país aparece em segundo lugar. Quanto aos dias de evento, há uma maior participação em apenas um dia do mesmo, seguida de uma equivalência de participação em dois dias e nos quatro dias de evento. Houve maior participação durante sábado e domingo devido às atrações do dia. Em relação a já ter participado do evento, é tido maioria como participando pela primeira vez, em destaque o público masculino, mas também havendo um grande número por parte do público feminino que vêm se introduzindo neste tema.

O objetivo específico segundo era apresentar as estruturas físicas e organizacionais dos eventos. O evento foi realizado na cidade de São Paulo no São Paulo Expo Exhibition \& Convention Center, que está localizado na Rodovia Imigrantes km 1.5. $O$ espaço conta com uma área de $100 \mathrm{mil} \mathrm{m}^{2}$ sendo 90 mil $\mathrm{m}^{2}$ de área apenas para exposição. O evento ocorreu nos dias 01, 02, 03 e 04 de dezembro de 2016. No primeiro dia o evento teve seu horário de início às $12 \mathrm{~h}$ e seu encerramento às $22 \mathrm{~h}$, nos segundo e terceiro dia teve seu horário estendido, com início às $10 \mathrm{~h}$ e encerramento às $22 \mathrm{~h}$ e, em seu último dia, no domingo, teve duração da $10 \mathrm{~h}$ às $20 \mathrm{~h}$. Na sua quarta edição, a Comic-Con Experience contou com um público de 196.000 pessoas circulando nos quatro dias de evento. Os participantes eram recepcionados por funcionários, devidamente uniformizados, na estação de metrô que os direcionavam ao longo do caminho prestando informações. Os organizadores do evento disponibilizaram transporte gratuito, em ônibus, da estação do metrô até o centro de exposições e vice-versa.

Chegando ao centro de eventos, os participantes eram direcionados ao estacionamento onde se localizava a secretaria para a retirada de credenciais e as filas para se direcionar ao evento. 
Ao chegar, na entrada, as pessoas eram revistadas por seguranças e após as credenciais eram conferidas junto a um documento de identificação (Figura 1).

Figura 1 - Entrada para o evento - conferência das credenciais

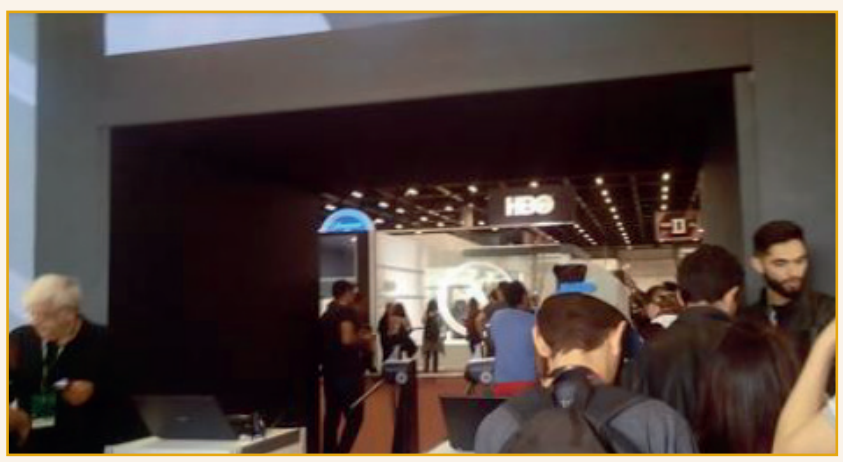

Fonte: acervo da autora (2017).

Em seu interior, a Comic-Con Experience teve sua estrutura geral dividida em seis áreas: expositores, artist alley ${ }^{5}$, painéis e atrações, praças de alimentação, áreas técnicas e sanitários. A parte dos expositores era dedicada às lojas de produtos especializados e os stands personalizados de filmes e comics. Nesta área era possível, além de fazer compras, participar de atividades e promoções. Como exemplo, havia o stand da série de jogos Assassin's Creed', que levou ao evento uma pista de obstáculos para a realização de parkour? , além de uma torre de cinco metros onde era possível realizar o Leap of Faith ${ }^{8}$ ou Salto da Fé, símbolo dos personagens (Figura 2 ao lado).

Ainda entre os stands presentes no evento, havia o dedicado à série Game of Thrones ${ }^{9}$, um dos mais movimentados, que trouxe itens originais da série além do famoso trono de ferro sím-

5 Tradução para beco dos artistas, área de exposição de artes de artistas independentes.

6 Série de jogos eletrônicos de ação-aventura criada pela empresa Ubisoft.

7 Esporte em que há a prática de transpor obstáculos em qualquer ambiente.

8 Marca registrada do jogo onde os personagens realizam um salto da fé de uma torre.

9 Série de TV baseada nos livros da saga As Crônicas de Gelo e Fogo de George R. R. Martin.
Figura 2 - Pista de obstáculos e ao fundo a torra para realização do salto

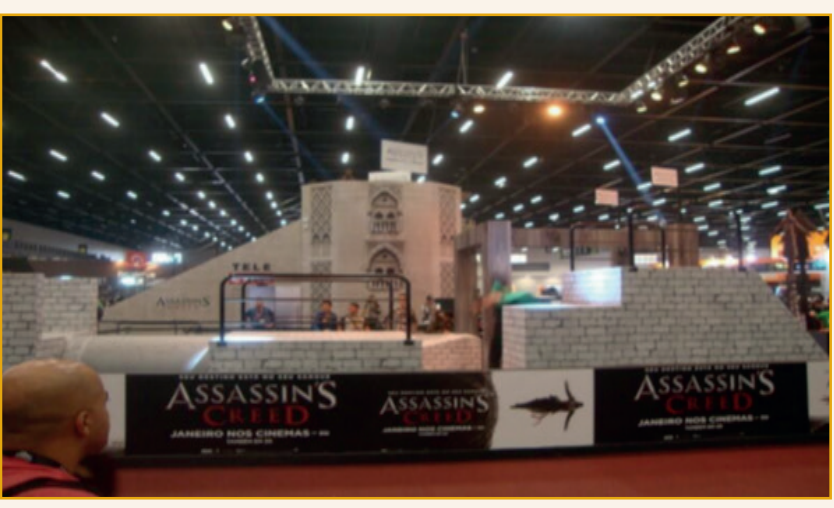

Fonte: Acervo da autora.

bolo da história e o stand da Turma da Mônica, que além de comprar produtos da marca era possível tirar fotos e ganhar o autógrafo do autor Maurício de Sousa.

O evento tinha uma área dedicada aos animes10 e mangás ${ }^{11}$ que contava com a presença de editoras e uma sala especial para atender aos cosplayers ${ }^{12}$ e exposições de figures ${ }^{13}$ em tamanho real das doze armaduras de ouro trazidas direto do Japão da saga Saint Seiya ${ }^{14}$ (figura 3).

Figura 3 - Stand com as armaduras da série Saint Seiya

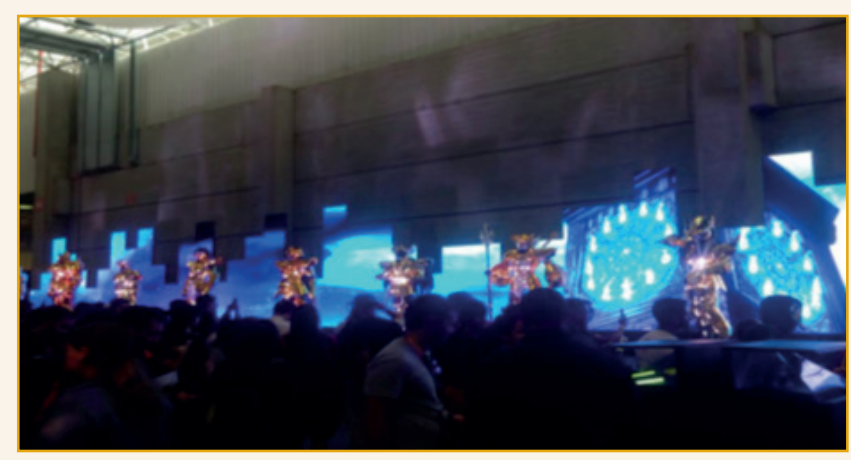

Fonte: Acervo da autora.

10 Desenhos animados de produção japonesa.

11 Historias em quadrinhos de produção japonesa.

12 Pessoas que se vestem como algum personagem e agem como os mesmos.

13 Imagens de algum personagem, podendo ser em tamanho real ou em menor escala.

14 Série de mangá japonês criada em 1986 por Masami Kurumada. 
O evento ainda contava com o stand da empresa Omelete, no local eram realizadas entrevistas com os convidados após os painéis em uma sala de vidro, assim permitindo aos participantes verem os convidados. A artist alley era uma área dedicada a artistas independentes que foram convidados a participar para expor suas artes. A área mais concorrida do evento era a dos painéis e atrações, que englobava os três auditórios onde artistas e convidados nacionais e internacionais conversavam de forma descontraída com a plateia. A sessão de fotos e autógrafos era o local para os participantes poder comprar passes para ter um momento com seu ídolo. A área era dividida em sete cabines onde os convidados especiais aguardavam para atender os participantes (Figura 4 ao lado).

O evento ainda contava com quatro praças de alimentação distribuídas ao longo do centro de exposições que oferecia uma diversidade de opções gastronômicas, além de áreas técnicas e os sanitários de fácil localização.
Figura 4 - Área de fotos e autógrafos

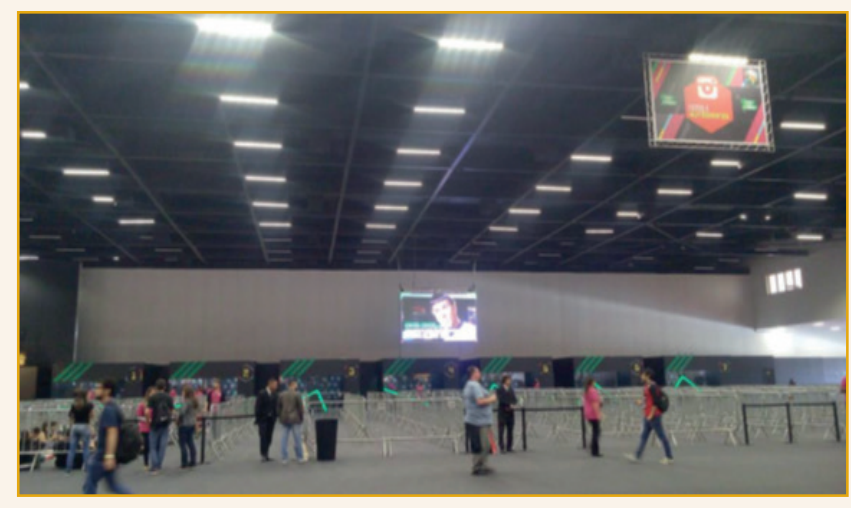

Fonte: Acervo da autora.

O objetivo específico terceiro era descrever os motivos que caracterizam os deslocamentos até o evento, dificuldades encontradas e satisfação com o evento. Para isso foram utilizadas questões com escalas de 1 a 5 , sendo 1 para pouco satisfeito e 5 para muito satisfeito. $\bigcirc$ primeiro item era relacionado aos motivos para a participação (Tabela 1).

Tabela 1 - Motivos para participação

\begin{tabular}{|l|c|c|c|c|c|}
\hline & \multicolumn{3}{|c|}{ N Média } & Mediana & Moda \\
\hline Q8.1 - Convidados especiais & 140 & 3,00 & 3,00 & 5 & 1,439 \\
\hline Q8.2 - Compra de produtos personalizados & 140 & 2,82 & 3,00 & 2 & 1,395 \\
\hline $\begin{array}{l}\text { Q8.3 - Novidades a serem anunciadas no mundo dos games, séries } \\
\text { e HQ's }\end{array}$ & 140 & 3,04 & 3,00 & 3 & 1,208 \\
\hline Q8.4 - Painéis e shows & 140 & 3,33 & 3,00 & 5 & 1,432 \\
\hline
\end{tabular}

Fonte: Elaboração da autora.

Ao observar a tabela 1 é possível destacar a questão 4, os painéis e shows, como maior motivador para participar do evento, com a maior média, de 3,33 e desvio de 1,432. Apesar de não figurar com a segunda maior média, a questão 1, convidados especiais, apresentou, assim como a questão 4, a moda na escala 5. Desse modo, percebe-se que os convidados, painéis e shows são os motivos principais para a participação no evento. A média mais baixa, assim como a moda, ficou com a questão 2, compra de produtos personalizados.
Dessa forma é possível fazer uma ligação com a citação de Lindon et al. (2004), que as motivações dos consumidores são classificados em três tipos: de caráter hedonista, de caráter racional ou utilitário e os de caráter éticos. Assim, os painéis e shows, o maior motivo para ir ao evento, entram na classificação de caráter hedonista, pois buscam um conjunto de prazeres e sentimentos agradáveis ao adquirir o produto/ serviço oferecido. Esses participantes procuram ter um momento agradável ao estar próximo de seus ídolos. 
Tabela 2 - Dificuldades para participação

\begin{tabular}{|l|c|c|c|c|c|}
\hline & Nédia & Mediana Moda & Desvio-padrão \\
\hline Q9.1 - Localização em relação a sua cidade e/ou estado natal & 140 & 2,47 & 2,00 & 1 & 1,327 \\
\hline Q9.2 - Localização do evento & 140 & 2,74 & 3,00 & 3 & 1,294 \\
\hline Q9.3 - Opções de transporte para o evento & 140 & 2,62 & 3,00 & 1 & 1,333 \\
\hline Q9.4 - Valores dos ingressos & 140 & 3,49 & 4,00 & 5 & 1,375 \\
\hline
\end{tabular}

$\mathrm{Na}$ tabela 2 foram questionadas as principais dificuldades encontradas para a participação no evento. Os respondentes tinham que indicar 1 para discordo totalmente e 5 para concordo totalmente. Os valores dos ingressos dos ingressos foram apontados como a maior dificuldade encontrada, com uma média de 3,49 e um desvio de 1,375. Os altos valores dos ingressos (que variaram entre $\mathrm{R} \$$
80,00 a $\mathrm{R} \$ 5000$ ) impossibilitaram algumas pessoas de participarem de mais de um dia do evento.

A questão que indicava a localização do evento em relação à cidade/estado natal recebeu a menor média $(2,47)$, assim como a menor moda (1). Esse cenário pode ser associado ao fato da maior parte dos participantes serem originários da cidade ou estado de São Paulo.

Tabela 3 - Satisfação com o evento

\begin{tabular}{|l|c|c|c|c|c|}
\hline & N & Média & Mediana & Moda \\
\hline Q10.1 - Organização e infraestrutura do local & 140 & 3,58 & 4,00 & 5 & 1,206 \\
\hline Q10.2 - Convidados especiais & 140 & 3,61 & 4,00 & 5 & 1,250 \\
\hline Q10.3 - Estandes de venda & 140 & 3,66 & 4,00 & $3 / 4$ & 1,098 \\
\hline Q10.4 - Divulgação do evento & 140 & 3,75 & 4,00 & 5 & 1,230 \\
\hline Q10.5 - Atendimento dos staffs & 140 & 3,79 & 4,00 & 5 & 1,267 \\
\hline
\end{tabular}

Fonte: Elaboração da autora.

A tabela 3 tem foco na satisfação dos participantes com o evento. Eles pontuaram 1 para totalmente insatisfeito e 5 para totalmente satisfeito. A questão 5 , atendimento dos staffs, teve a maior média $(3,79)$, assim como a moda (5), e desvio de 1,267, mostrando assim que funcionários selecionados prestaram um bom atendimento aos visitantes. A outra questão que apresentou a segunda maior média foi a da divulgação do evento, com média de 3,75 e desvio de 1,230. Os produtores investiram em um marketing em longo prazo, e dessa forma divulgavam o evento constantemente ao longo do ano. Foram utilizadas as redes sociais assim como os e-mails pessoais de participantes antigos para realizar a divulgação.

Apesar de ter a segunda menor média $(3,61)$, a questão 2, convidados especiais, apresentou a moda no grau 5. Uma das respostas encontradas para este cenário está no fato de que alguns convidados já haviam se apresentado em edições anteriores, ou seja, não havia ineditismo para quem frequenta anualmente o evento. De todo modo, a satisfação com o evento de um modo geral recebeu médias mais altas em relação às motivações e dificuldades encontradas para a participação. Por fim, os participantes foram questionados sobre a 
quantidade de edições do evento que eles gostariam que fossem realizadas ao longo do ano.

Gráfico 8 - Quant. de eventos ao longo do ano

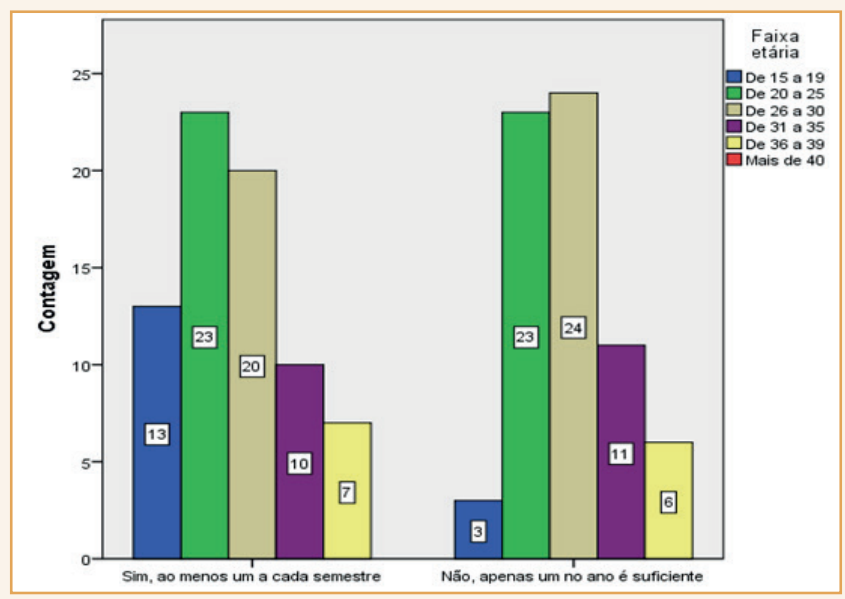

Fonte: Elaboração da autora.

Ao observar o gráfico 8 é possível a divisão dos grupos da faixa etária entre 20 e 30 anos, ou seja, que gostariam tanto semestralmente quanto anualmente. Esse resultado reforça as ações da produtora Omelete, que já investiu em uma nova edição do evento que foi lançada no mês de abril de 2017. Nomeada como Comic-Con Experience Tour, a primeira edição da turnê foi realizada na região Nordeste do Brasil em Pernambuco, Reci$\mathrm{fe}$, e seguiu os mesmos moldes da edição anual realizada no fim do ano em São Paulo.

\section{Conclusão}

O objetivo principal da pesquisa foi o de analisar um evento de grande porte com temática voltada para o público nerd/geek. Para obtenção dos resultados foi utilizado uma pesquisa estruturada quantitativa aplicada junto aos participantes em um dos dias do evento. A pesquisa procurou descobrir o perfil do público participante, as estruturas montadas para atender a demanda e a motivação, as dificuldades e satisfação que tiveram com o evento.

O público nerd/geek foi escolhido como objeto desta pesquisa, pois cada vez mais vem ganhando um número de adeptos deste estilo. Desta forma os eventos voltados para eles vêm crescendo e se adaptando para melhor atender a de- manda. A Comic Con, que tem origem nos Estados Unidos, é o maior modelo para a realização de uma festividade deste porte. Este evento, introduzido no Brasil em 2014, assim como outros que ocorrem ao longo do ano em diferentes cidades, busca atender aos desejos e fantasias que o público alvo está acostumado a ver, seja em suas séries, quadrinhos ou animações, desta forma proporcionando um escape da realidade diária e os transportando aos mundos dois quais são fãs.

Durante a pesquisa em campo foram observadas dificuldades e limitações para a sua realização, deste modo é possível salientar a grande área disponível para o evento gerando assim uma alta movimentação e muito barulho impossibilitando entrevistar os participantes com calma. Outro fator a ser observado era de que o evento possuía muitas atividades interativas o que fazia com que não houvesse um tempo hábil de entrevista com o público que tinha atenção voltada para as atividades. Um ponto positivo, para a pesquisa, eram as filas criadas por conta do grande número de pessoas, que geravam lentidão e um grande tempo de espera, o que possibilitou entrevistar os participantes com maior calma.

A pesquisa junto aos participantes retornaram resultados positivos nos três objetivos a serem analisados. Os convidados especiais se destacaram como sendo os maiores motivadores para os geeks participarem desses eventos, respondendo desta forma o objetivo geral deste estudo, a necessidade das pessoas em estarem na presença de seus ídolos. As suas satisfações com o evento, desde as estruturas montadas ao atendimento dos staffs e as atrações proporcionadas foram avaliadas positivamente mostrando assim que o evento conseguiu atender as necessidades do público. A pesquisa em campo proporcionou também fazer uma análise do público, desta forma podendo caracteriza-lo e o relacionar ao referencial teórico escrito.

Por fim, o presente trabalho teve por maior objetivo contribuir para futuras pesquisas na área de eventos em especial aos voltados para o público geek em ascensão. Como sugestão, para futuros trabalhos, indica-se esse estudo visando também os impactos econômicos gerados por este evento na capital Paulista, assim como um número maios na coleta de dados junto aos participantes. 


\section{Referências}

AJZEN, l.; FISHBEIN, M. Attitude-Behavior relations: A theoretical analysis and review of empirical research, Psychological Bulletin, v. 84, 1977.

AL.EN, J; et al. Organização e gestão de eventos. Rio de Janeiro: Campus, 2008.

ANDRADE, R. B. Manual de eventos. Caxias do Sul: EDUCS, 2002.

BARBOSA, F. S. Planejamento estratégico para eventos: um estudo de caso das estratégias de marketing utilizadas pela Oktoberfest de Santa Cruz do Sul/RS. Revista de cultura e turismo, n.1, p.94, 2013.

BRASIL. Ministério do Turismo. Fundação Getúlio Vargas. Boletim de Desempenho Econômico do Turismo. Ano XIII, n. 51, 2016.

BRASIL. Ministério do Turismo. Fundação Getúlio Vargas. Boletim de Desempenho Econômico do Turismo. Ano XIV, n. 53, 2017.

BRASIL. Ministério do Turismo. Fundação Getúlio Vargas. Pesquisa do impacto econômico dos eventos internacionais realizados no Brasil 2007/2008. 2009.

BRASIL. Portal Brasil. Setor de eventos alavanca no Brasil. 25 jun. 2013.

Disponível em: <http://www.brasil.gov.br/esporte/2013/06/setor-de-eventos-no-brasil-cresceu-23>. Acesso em: 09 set. 2016.

FELDMAN, R. Compreender a Psicologia, Lisboa, McGraw-Hill de Portugal, 2001.

FRANCISCO, K. C. A cultura juvenil, a mídia e o apelo ao consumo. In: Revista Eco-Pós, v. 13, n. 1, 2010.

GALVÃO, D. Os nerds ganham poder e invadem a TV. Revista Científica Intr@ciência, São Paulo, n. 1, 2009.

GETZ, D. Event Tourism: Definition, Evolution, and Research. Tourism Management, v. 29, n.3, 2008

GIL. A C. Como elaborar projetos de pesquisa. 4 ed. São Paulo. Atlas, 2007.

GNOTH, J. Tourism motivation and expectation formation. Annals of Tourism Research, v. 21, n. 2, 1997.

GRENHAS, M. C. Motivação, satisfação e fidelização dos visitantes do festival mediterrâneo de loulé. Universidade Algarve, 2013.

IPA, Centro Universitário Metodista do. Manual de elaboração de trabalhos acadêmicos: referenciados pelas normas gerais conforme a ABNT. Porto Alegre. Centro Universitário Metodista IPA, 2016.

ISO-AHOLA, S. E. Towards a social psychology theory of tourism motivation, A rejoinder, Annals of Tourism Research, v.9, n.2, 1982.

JOVEM NERD. Quem Somos. Disponível em <https://jovemnerd.com.br>. Acesso em 12 out. 2016.

Lee, C. K, e T.H. Lee. World Culture EXPO segment characteristics, Annals of Tourism Research, v.28, n.3, 2001.

LINDON, D., et al. Mercator XXI: Teoria e Prática do Marketing, 10. ed. Lisboa Publicações Dom Quixote, 2004.

LUNDBERG, D. E. Why tourists travel, Cornell HRA Quarterly, February, 1971.

MACCANNELL, D. The tourist, New York, Schockon, 1977. 
MARCONI, M. A. e E. M. Técnicas de pesquisa. 6 ed., São Paulo: Atlas, 2007.

MARUJO, N. Turismo, Turistas e Eventos: O Caso da llha da Madeira. 2012.

MARUJO, N. TURyDES: Revista Turismo y Desarrollo local. Os eventos turísticos como campo de estudo académico, v. 7, n. 17, 2014.

MATOS, P. O nerd virou cool: identidade, consumo midiático e capital simbólico em uma cultura juvenil em ascensão. XVI Congresso de Ciências da Comunicação na Região Sudeste, São Paulo, SP, 2011.

MEIRELLES, G. F. Tudo sobre eventos. São Paulo: STS, 1999.

OLIVEIRA, A. S. A importância da captação de eventos para o Brasil. Universidade Estácio de Sá, Rio de Janeiro, 2007.

PRODANOV, C. C. e FREITAS, E. C. Metodologia do trabalho cientifico: métodos e técnicas da pesquisa e do trabalho acadêmico. Rio Grande do Sul, Universidade FEEVALE, 2013.

SÃO PAULO EXPO. <http://saopauloexpo.com.br/index.php>. Acesso em 03 abr. 2017.

SCOTT, D. A comparison of visitors' motivations to attend three urban festivals, Festival Management \& Event Tourism, n.3, 1996.

SHEU, J.; CHU, K. Mining association rules between positive word-of-mouth on social network sites and consumer acceptance: a study for derivative product of animations, comics, and games. Telematics and Informatics, v. 34, n. 4, p. 22-33, 2017.

SUPERINTERESSANTE. O que são os jogos chamados RPG. Disponível em <http://super.abril.com.br/ tecnologia/o-que-sao-os-jogos-chamados-rpg>. Acesso em 07 out. 2016.

ZANELLA, L. C. Manual de organização de eventos: planejamento e operacionalização. São Paulo, Atlas, 2003. ZARA, A. A força dos nerds. C\&S, São Paulo, n. 33, p. 18-25, Julho/Agosto 2014. 